\title{
Questões DE EQUIVALÊNCIA MÉTRICA \\ EM TRADUÇÃO DE POESIA ANTIGA
}

\author{
Issues of metrical equivalence in \\ translation of ancient poetry
}

\author{
Marcelo Tápia*
}

\begin{abstract}
RESUMO
O artigo discute diferentes modos de adaptação de padrões métricos clássicos para línguas modernas, particularmente para o português, buscando examinar noções diversas de equivalência métrica que orientam os referidos modos e os resultados por eles determinados.

Palavras-chave: tradução de poesia antiga; equivalência métrica; adaptação de padrões métricos clássicos; versificação clássica e moderna; hexâmetro.
\end{abstract}

\begin{abstract}
The article discusses different modes of adapting classic metrical patterns in modern languages, particularly in Portuguese, seeking to examine various notions of equivalence in metrics that guide these modes and the results determined by them.

Keywords: translation of ancient poetry; metrical equivalence; adaptation of classic metrical patterns; classical and modern versification; hexameter.

Paulo). 
The unacknowledged contours of the ancient meter can at times be sensed beneath the verse and prose of modern writers, especially those with classical training. James Joyce's Ulysses (1922) opens with 14 syllables cadenced as a dactylic hexameter, spondaic in the fifth foot.

G. Braden ${ }^{1}$

Qual a tarefa do tradutor? O que ele deve realizar, no caso de tradução de poesia e, em particular, no caso da tradução de poesia greco-latina? Inevitavelmente, o tradutor se orientará por propósitos específicos de aproximação, em diversos aspectos, de seu texto ao texto fonte.

A busca pelo estabelecimento de correspondências entre o texto traduzido e o original, que envolve diferentes noções acerca de fidelidade, encerra, fundamentalmente, a ideia de equivalência. Esta consiste, na visão de Anthony Pym, num dos paradigmas em que se podem enquadrar as teorias da tradução; e tratar-se-ia de um paradigma persistente: para o autor, os princípios básicos da equivalência, em suas diferentes versões, "subjazem na maior parte do trabalho realizado em tradutologia" ${ }^{2}$. Pym constata que a equivalência não morreu, ainda que tenha sido questionada pelo pós-estruturalismo, particularmente pelo pensamento desconstrucionista ${ }^{3}$.

Admitido como persistente, como deve ser entendido o paradigma de equivalência ${ }^{4}$ no processo de tradução de poesia e, especialmente - focalizando-se o objeto de interesse deste artigo -, de poesia clássica?

Veja-se o que diz, em sua tese de doutorado ${ }^{5}$ - voltada à tradução das Odes Píticas de Píndaro -, o tradutor Leonardo Antunes:

1 A epígrafe integra o texto do verbete "Hexameter", de: GREENE, Roland (editor in chief). The Princeton Encyclopedia of Poetry \& Poetics. 4. ed. Princeton e Oxford: Princeton University Press, 2012. p. 627-629. A afirmação, embora incerta, sugere a presença e a influência, ainda quando não explícitas, da poética clássica sobre a literatura moderna.

2 PYM, Anthony. Teorias contemporaneas de la traducción. In: site da Universitat Rovira i Virgili. Tarragona (Catalunha, Espanha): 2011, p. 111. O estudo, estruturado "em torno de paradigmas, e não de teorias, teóricos ou escolas individuais", examina os paradigmas baseados em "equivalência", "finalidade", "descrição", "indeterminação" e "localização".

3 Duas são as "razões profundas", mencionadas por Pym, para as dúvidas teóricas relativas à equivalência: a "instabilidade da "origem'” ("a investigação descritiva mostra que as tarefas dos tradutores variam consideravelmente em função de seu posicionamento cultural e histórico") e o "ceticismo epistemológico" que pôs em dúvida as "certezas" próprias das diversas formas de estruturalismo.

4 Para Pym, "La equivalência [...] dice que la traducción tiene el mismo valor que el texto de origen, o al menos algún aspecto de dicho texto. A veces ese valor se encuentra a nivel formal $[\ldots]$; a veces se halla a nivel referencial [...]; y otras veces a nivel funcional [...]". Op. cit., p. 23.

5 ANTUNES, Carlos Leonardo Bonturim. Métrica e rítmica nas Odes píticas de Píndaro. Tese (Doutorado) - Departamento de Letras Clássicas e Vernáculas, FFLCH-USP, São Paulo, 2013. 
Para nossa tradução, desejávamos propor uma solução que mimetizasse, de alguma forma, a estrutura métrica e rítmica que identificamos tanto nas odes $\mathrm{D} / \mathrm{e}$ quanto nas odes logaédicas, visto que essas características são partes fundamentais de sua sonoridade. A forma que encontramos para tanto foi a de tomar algumas licenças, baseadas nos próprios recursos empregados pelo poeta, a fim de reconstruir em Português um ritmo semelhante àquele identificado no Grego.

Note-se, na citação, o objetivo expresso de "reconstituição do ritmo", e, no parágrafo seguinte, a afirmação relativa à "maneira" de traduzir:

Essa proposta é diferente da maneira que geralmente se traduz Píndaro no âmbito acadêmico. Nosso enfoque não é no sentido, como comumente se faz, mas no ritmo e na sonoridade. [...]

Nosso objetivo, portanto, é trazer essa sonoridade para uma tradução em Português por meio de um método rigoroso e embasado em fundamentos teóricos previamente delimitados, os quais, ao mesmo tempo, procuram elucidar a própria essência da métrica e da rítmica pindária.

Pode-se observar que o propósito de correspondência entre o poema traduzido e o original encerra uma noção de equivalência, no caso desse autor, diferente, em sua visão, daquela mais habitual no "âmbito acadêmico", que se caracterizaria pelo enfoque "no sentido". A apregoada necessidade de correspondências formais, em tradução poética, tem vasta fundamentação, em diversos segmentos dos estudos linguísticos e literários ${ }^{6}$. No caso de Antunes, tais correspondências se voltam, como se poderá constatar, à ideia de uma estrita correlação entre os esquemas métricos do texto traduzido e do original:

Essa tradução foi realizada de forma a mimetizar, de forma bastante próxima, os dois padrões métricos e rítmicos que acreditamos ter identificado nas odes de Píndaro.

Esses poucos recursos nos permitem fazer uma aproximação métrica dos poemas, a qual se completa e sustenta a partir da visão rítmica que propomos de que haja uma equivalência (por meio de

6 Um conjunto ensaístico a se destacar, entre nós - pela amplitude das reflexões que encerra, e pelo que aponta de fontes referenciais sobre o tema, das quais se vale -, é o que reúne artigos de Haroldo de Campos relativos à sua teoria da transcriação. Veja-se: TÁPIA, Marcelo; NóBREGA, Thelma Médici (orgs.). Haroldo de Campos - Transcriação. São Paulo: Perspectiva, 2013. 
pausas ou prolongamentos) entre esquemas métricos semelhantes (como um glicônio e telesíleo por exemplo) dentro dessas odes. [...] se se fizesse uma melodia para o texto Grego, usando a distribuição temporal que identificamos em nossas análises rítmicas, a mesma melodia poderia ser usada para o texto em Português.

[...] um exemplo da tradução da primeira tríade ou estrofe:

Exemplo: Pítica $I X, \mathrm{~s} 01$

Esq. Greg.: $\quad-\cup|--|-\cup|--\|-\cup \cup|-\cup \cup| \sqcup\|$

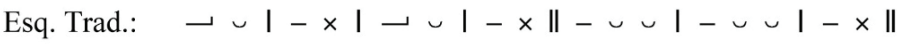

Tradução: $\quad$ Áurea lira, posse em comunhão para Apolo e pras Musas

Como se vê, o autor considera que pode haver, em sua tradução, uma exata equivalência métrico-rítmica aos versos gregos, embora haja, em princípio, uma diferença essencial entre os sistemas de composição em ambas as línguas - o verso grego baseia-se num sistema quantitativo (que considera a duração das sílabas: as longas duram o dobro das breves), e não qualitativo (fundamentado na distinção entre sílaba tônica e sílaba átona), como o verso em nosso idioma. $O$ caminho pretendido de equivalência se viabiliza, contudo, no conceito de "compasso" como unidade dos versos, voltada à ideia de musicalização dos poemas.

Mas, antes de prosseguirmos com observações sobre tal proposta, que nos será útil para os objetivos deste artigo, comentemos que a já longa história de adaptação de padrões métricos antigos a idiomas neolatinos abrange diferentes concepções sobre os modos de correspondência entre os sistemas diversos de metrificação. Conforme explicita um verbete de The Princeton Encyclopedia of Poetry \& Poetics ${ }^{7}$, desde a Renascença houve tentativas de introduzir os princípios métricos do verso clássico greco-latino na versificação das línguas vernáculas - motivados pelo prestígio da poesia clássica, muitos escritores tomariam o verso clássico como referência para ampliar "a variedade de formas métricas em suas próprias tradições literá-

7 ARTRIDGE, D. Trata-se do verbete "Classical meters in modern languages", in: $o p$. cit., p. 250-252. 
rias"; tais tentativas teriam se dado especialmente nos séculos XV e XVI. Em torno do século XVII, as tradições do verso nativo se afirmariam, reduzindo-se a motivação para se adotarem Grécia e Roma como modelos; contudo, o desejo romântico de desafiar formas de verso estabelecidas produziria um ressurgimento do interesse em metros clássicos, especialmente na Alemanha (F. G. Klopstock) e na Inglaterra (S. T. Coleridge, Robert Southey), e o surgimento de um classicismo mais informado historicamente, no final do século XIX e início do XX, resultaria em novas tentativas de se conceberem equivalentes vernaculares exatos para os metros greco-latinos.

Distinguem-se, no referido verbete, dois tipos gerais de imitação de metros clássicos: o primeiro, o que busca estabelecer um princípio de quantidade no vernáculo para fundamentar a escansão; o segundo, o que mantém a proeminência fonológica da língua em questão como o marcador do metro, mas procura imitar ou reproduzir os padrões métricos de determinado verso.

Os dois tipos apresentados integram o conjunto definido no panorama da adaptação do metro clássico próprio da poesia épica (o hexâmetro dactílico $^{8}$ ), elaborado por Francisco Pejenaute ${ }^{9}$. Segundo esse autor, um dos modos a se distinguirem de adaptação do hexâmetro ao espanhol correspondente ao primeiro tipo de imitação já identificado - é aquele da "adaptação à maneira greco-latina", que procura considerar a duração das sílabas na língua vernácula, simulando-se o verso quantitativo, como neste exemplo de autoria de D. Sinibaldo de Mas (1809-1868), poeta que formulou regras de quantidade em castelhano inspiradas em regras de quantidade nas línguas clássicas:

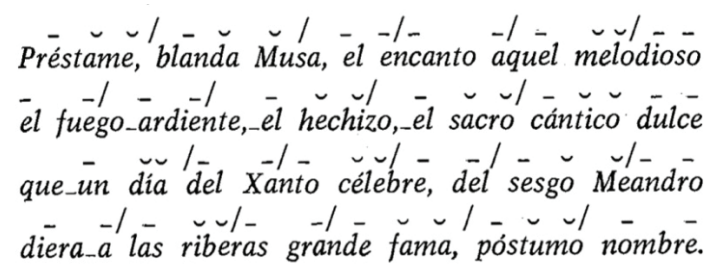

8 Verso composto de seis pés dáctilos, isto é, seis unidades formadas por uma sílaba longa e duas breves, sendo que estas podiam ser substituídas por uma sílaba longa, gerando a mudança do dáctilo em espondeu (pé formado por duas sílabas longas); as substituições determinavam uma dinâmica, ou variabilidade rítmica dentro do padrão métrico.

9 PEJENAUTE, F. La adaptación de los metros clasicos en castellano. Estudios clasicos, Madrid, n. 63, p. 213, 1971. 
A tentativa é, portanto, de fazer valer a diferença de duração entre sílabas do espanhol; o comentário de Pejenaute sobre essa opção aponta a não funcionalidade relativa ao sistema, diante de um padrão instalado de leitura com base em tônicas: "Si algún ritmo tienen versos de este tipo, proviene delos acentos que, al final, aparecen según la fórmula de la cláusula hexamétrica $\div--/ \div-"$.

Entre outros modos apontados por Pejenaute, encontra-se o da “adaptação pelo sistema 'scandere'” (correspondente ao segundo tipo de imitação antes mencionado), que compreende o estabelecimento da correspondência entre a sílaba longa dos versos antigos e a sílaba tônica das línguas modernas, assim como entre a sílaba breve e a sílaba átona, padrão este identificado com a tradição anglo-saxã de versificação. ${ }^{10}$ Uma das submodalidades desse sistema seria o "hexâmetro dactílico puro", como o praticado por Pedro-Luis Heller, em sua tradução da Iliada, de Homero:

Esta, pues, / fue hacia / él; y la / criada se/guia sus / pasos, sobre su / seno lle/vando al / cándido, / tierno in/fante, ${ }^{11}$

Conforme é bem conhecido, essa opção adaptativa - passível de crítica pela regularidade e consequente "monotonia" que sua rítmica encerra, diferente da dinâmica própria dos versos baseados no sistema quantitativo - foi a adotada pelo poeta e tradutor brasileiro Carlos Alberto Nunes, como ilustram os versos seguintes:

Musa, reconta-me os feitos do herói astucioso que muito

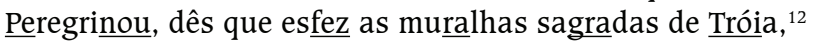
$[\ldots]$

Contudo, o emprego do sistema acentual na versificação de língua portuguesa - forma mais comum de adaptação de padrões métricos clássicos - encontra, historicamente, resistências, devido ao conceito predominante da distinção entre os princípios de versificação das línguas germânicas e os das neolatinas. A esse respeito, lembre-se o que afirma Wolfgang Kayser:

10 Esta, a partir da adoção de tal correspondência, caracteriza-se pelo emprego dos esquemas clássicos baseados em pés - como tão bem se sabe-, construindo-se sobre versos jâmbicos, trocaicos e outros, correspondentes aos demais pés. Consulte-se a respeito, por exemplo: KAYSER, W. Análise e interpretação da obra literária. Coimbra: Arménio Amado Editor / São Paulo: Livraria Martins Fontes, 1976.

11 Pejenaute, op. cit., p. 230.

12 HOMERO. Odisseia. Trad. Carlos Alberto Nunes. 4. ed. Rio de Janeiro: Ediouro, 2001. 
Um leitor português está habituado a que a ordem consista numa contagem fixa de sílabas, e na fixação de alguns acentos. De maneira semelhante se costuma estruturar o verso também nas outras línguas românicas. [...]

[No verso germânico,] as sílabas são "pesadas", i. é, segundo o grau tônico, incluem-se nas duas categorias das sílabas tônicas e átonas. O verso apresenta-se como uma série ordenada de sílabas acentuadas e não acentuadas. Dentro do verso surgem assim pequenas unidades que são designadas como pés ou compassos (Takte). ${ }^{13}$

Em importante ensaio sobre versificação, Péricles Eugênio da Silva Ramos procura demonstrar que "se existe um abismo, em teoria, entre os sistemas germânico e novilatino, na prática desaparece esse abismo" ${ }^{14}$. Após observar que Kayser teria repetido o que dizem os "manuais correntes de metrificação portuguesa" - segundo os quais o sistema germânico seria silábico-acentual, e o das línguas neolatinas, silábico -, Ramos se vale de exemplos para mostrar que, se por um lado, os padrões germânicos de pés são relativizados pela ocorrência de fenômenos que "contrariam a regra", falando-se em "substitution" (que pode ser anáclase ou "colocação de um pé trissilábico por um iambo, no blank verse”), por outro, a escansão - por exemplo - de versos camonianos (ou de poetas pré-românticos, como Silva Alvarenga, e românticos, como Castro Alves) indicam "pentâmetros iâmbicos patentíssimos”, entre outros versos silábico-acentuais.

As adaptações de metros clássicos em bases acentuais não seriam, assim, estranhas à tradição da versificação em nossa língua e em outros idiomas neolatinos. Houve e há, no entanto, como se mencionou, resistência a tal concepção, conforme também o demonstra, no século XIX, a observação de Antonio Feliciano de Castilho (1800-1875) na primeira edição de seu Tratado de metrificação (1858):

[...] A tentativa não já moderna, mas em que tanto insistiu modernamente o nosso, aliás bom engenho, Vicente Pedro Nolasco, de fazer versos portugueses hexâmetros e pentâmetros, é uma quimera sem o mínimo vislumbre de possibilidade.

13 op. cit., p. 82. O próprio Kayser menciona, contudo (referindo-se a modelos de odes clássicas), que "a adaptação da métrica antiga das odes também foi tentada nas línguas românicas, ocasionalmente até com a aceitação do sistema quantitativo [...] Porém, tal qual como nas literaturas germânicas, [...] não pôde dar resultado esta tentativa. Op. cit., p.92.

14 RAMOS, Péricles Eugênio da Silva. Os princípios silábico e silábico-acentual. In: $O$ verso romântico e outros ensaios. São Paulo: Conselho Estadual de Cultura, 1959. p. 25. 
O próprio Castilho, contudo, expressaria opinião diversa a respeito dos padrões adaptativos em edição posterior de seu Tratado ${ }^{15}$, que traz exemplos de utilização de padrões métricos clássicos, incluindo-se poemas nos quais se atribui duração a sílabas do português (adaptação à maneira greco-romana). Ainda que este modo de adaptação cause-nos estranheza, e não tenha efetivamente vingado como referência em composição e tradução poéticas ${ }^{16}$, a correspondência entre longas e breves, de um lado, e tônicas e átonas, de outro, é aludida na terminologia usada por Olavo Bilac e Guimarães Passos em seu Tratado de versificação (1910); nele, os autores utilizam as acepções "longa" e "breve" para se referirem às sílabas do verso em português. Diz o texto:
O acento predominante ou a pausa numa palavra é aquela sílaba em que parecemos insistir, assinalando-a [...]
O som mais ou menos aberto da vogal não influi sobre o acento; a demora é, na pronunciação, o que o caracteriza. [...]
A sílaba longa é que dá à palavra o nome de aguda, grave ou esdrúxula $[\ldots]^{17}$

Bilac e Passos, assim como outros teóricos da versificação, encontram apoio na lição do mesmo Castilho, que, em seu Tratado, reconhecia sílabas longas e breves nas palavras:

Acento predominante ou pausa num vocábulo se chama aquela sílaba em que parecemos insistir, ou deter-nos mais, v. g.: em

15 Na edição de 1874 do Tratado, o autor emenda o seguinte comentário: "Entretanto, agora, [...] refletindo novamente na matéria, confessamos que a exclusão absoluta que fazíamos da metrifícação latina para o português já nos não parece tão bem fundada. Subsiste sim a objeção de não haver em nossa língua as quantidades, como havia no latim; mas a essa pode-se responder que os entendedores desse belo idioma, dado o não saibam pronunciar, nem por consequência lhe possam conhecer as longas e as breves, não deixam contudo de reconhecer a harmonia dos versos de Virgílio ou de Ovídio [...] Esta só ponderação já persuade que o nosso ouvido, que assim aprecia esses metros pronunciados sem a respectiva prosódia antiga, e à portuguesa, bem pode por analogia achar música aceitável nos que em português se lhes assemelharem. (CASTILHO, A. F. de. Tratado de metrificação portuguesa - Seguido de considerações sobre a declamação e a poética. 4. ed, revista e aumentada. Lisboa: Livraria Moré-Editora, 1874. (Nesse fragmento, cuja escrita é datada de 1871, Castilho refere-se a terem se passado quatro anos desde a quarta edição, o que mostra tratar-se de edição nova, ainda que permanecesse como "quarta").)

16 A conclusão é sugerida, por exemplo, por Pejenaute, em citação incluída neste estudo.

17 BILAC, Olavo; PASSOS, Guimaraens. Tratado de versificação. Rio de Janeiro: Livraria Francisco Alves, 1910. p. 44-45. 
louvo, a primeira; em louvado, a segunda; [etc.]

Toda a palavra tem necessariamente uma pausa, nem mais, nem menos. [...]

Levantamos tem a terceira sílaba longa seguindo-se-lhe por consequência uma só breve; se juntando-lhe o complemento nos - disserdes levantamo-nos, sentireis depois daquela sílaba longa, não já uma só breve, mas duas breves; $[. . .]^{18}$

A possível correspondência entre as noções de sílabas longa/breve e tônica/átona aponta para a pertinência da escolha de se realizarem, em línguas modernas, versos imitativos de padrões métricos clássicos a partir da tonicidade das sílabas no idioma vernáculo. A noção de duração das sílabas na versificação em línguas modernas encontra sustentação nos modos de abordagem do verso com base na notação musical, conforme proposta de Geoffrey N. Leech ${ }^{19}$, de M. Cavalcanti Proença ${ }^{20}$ (que, por sua vez, menciona Spinelli e Echarri) e de Paulo Henriques Britto: em comum a esses autores, a indicação, por meio de símbolos musicais convencionais, da "duração relativa das sílabas e [d]as pausas e [d]as separações entre compassos" ${ }^{21}$. Veja-se, como exemplo, uma notação apresentada por Leech $^{22}$ :

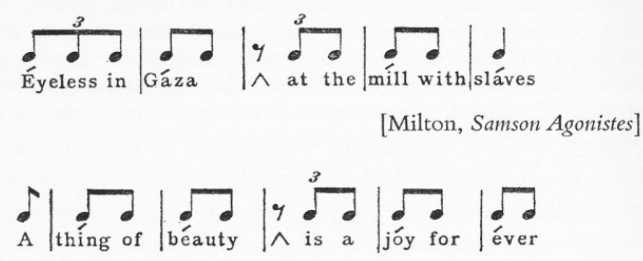

[Keats, Endymion, I]

Ainda que as visões mencionadas sobre versificação em línguas modernas apontem para uma conciliação com os padrões antigos de metrificação, aproximando-os (e aproximando o modo de conversão dos metros das línguas anglo-saxãs daquele dos idiomas neolatinos), é inegável - como já se afirmou - a diferença entre os sistemas próprios das línguas antigas

18 CASTILHO, A. F. de. Tratado de metrificação portuguesa - Para em pouco tempo, e até sem mestre, se aprenderem a fazer versos de todas as medidas e composições. Lisboa: Imprensa Nacional, 1851. p. 14-15.

19 LEECH, G. A linguistic guide to English Poetry. London: Longman, 1969.

20 PROENÇA, M. Cavalcanti. Ritmo e poesia. Rio de Janeiro: Organização Simões, 1955.

21 BRITTO, P. H. O conceito do contraponto métrico em versificação. Poesia Sempre, Rio de Janeiro, n. 31, p. 71-83. 2009.

22 op. cit., p. 108. 
- nos quais a duração das sílabas (fundamento da identidade das unidades rítmicas) $e$ sua acentuação constróem a dinâmica do verso - e os sistemas adaptativos usados nas línguas modernas - baseados essencialmente na tonicidade silábica. Tal diferença permite que, apesar dos esforços de metrificação em que se procura atribuir valor de duração às sílabas independentemente de sua tonicidade - como o exemplo fornecido por Pejenaute -, os versos resultantes de tal procedimento sejam lidos a partir da configuração acentual que encerram. ${ }^{23}$

O problema da correspondência - ou da equivalência - entre os sistemas quantitativo e qualitativo de versificação persistem, portanto. Sobre o tema, diz o tcheco Jirí Levy no tópico "Traduzindo a partir de sistemas não-cognatos de versificação", de seu livro denominado, na versão em inglês, The art of translation:

[...] este princípio de imitação do metro pela substituição de uma característica por outra característica é bastante simples, mas [...] dá origem a uma série de questões estéticas...

[...] o metro clássico, quando adaptado a um princípio prosódico diferente, próprio de outra língua, adquire novas qualidades que não estavam presentes no original. [...]

[outra questão fundamental] é se os leitores contemporâneos, entre os quais a familiaridade com o metro clássico continua a diminuir, são capazes de apreender muitas estrofes complexas (alcaic, saphic etc) e quanto eles considerarão livres estes versos. $^{24}$

23 Veja-se minha tese de doutorado, Diferentes percursos de tradução da épica homérica como paradigmas metodológicos de recriação poética - um estudo propositivo sobre linguagem, poesia e tradução, apresentada ao Departamento de Teoria Literária e Literatura Comparada da FFCL-USP, em 2012. Nas p. 253 e seguintes, são feitos exercícios de escansão silábico-acentual de poemas baseados na adaptação do hexâmetro dactílico "à maneira greco-latina" (ou seja, elaborados a partir da adoção de um sistema quantitativo), considerando a leitura tradicional e habitual dos versos das línguas modernas; foi possível constatar, então, a recorrência de padrões de distribuição das tônicas, que trazem funcionalidade rítmica aos versos quando lidos com base na tonicidade das sílabas. A conclusão vai ao encontro da ideia do prevalecimento da percepção do ritmo por meio da leitura convencional, mesmo nos versos compostos com base na imitação de padrões quantitativos. Também se revelou a possibilidade de uma leitura identificadora de padrões silábicos tradicionais em língua portuguesa, que podem ser empregados conforme esquemas de justaposição de dois versos de medida usual (o modo da "justaposição" é um dos padrões identificados por Pejenaute para a adaptação do hexâmetro dactílico; entre nós, é notável a utilização do sistema pelo tradutor André Malta, em sua tradução dos cantos I, IX, XVI e XXIV da Ilíada, na qual justapõe dois versos heptassílabos - ver: MALTA, André. A selvagem perdição - Erro e ruína na Ilíada. São Paulo: Odysseus, 2006).

24 LEVY, J. The art of translation. Translation: Patrick Corness. Amsterdam / Philadelphia: John Benjamins Translation Library, 2011. p. 205-209. 
Mesmo no caso de adaptação de um padrão rítmico uniforme, como a realizada por Carlos Alberto Nunes para o hexâmetro dactílico, é recorrente a qualificação dos versos por ele adotados em sua recriação da Odisseia e da Ilíada, de Homero, e da Eneida, de Virgílio, como "versos de dezesseis sílabas" ${ }^{25}$, evidenciando-se a tendência de reconhecimento de padrões métricos conforme a expectativa gerada pela tradição de versificação em língua portuguesa. Talvez as recentes iniciativas ${ }^{26}$ - mesmo entre nós, como as do referido Leonardo Antunes e do também tradutor Érico Nogueira - acabem por contribuir para um mais habitual reconhecimento de padrões adaptativos de metros antigos em composições realizadas em português.

A opção por recriar padrões métricos clássicos em esquemas usuais na versificação em nossa língua é comum a tradutores notórios, como é o caso de Manuel Odorico Mendes (que adota a solução camoniana do decassílabo para o verso heroico) e de Haroldo de Campos, que se valeu do dodecassílabo, tradicionalmente considerado o maior verso do idioma. A busca de equivalência aos versos clássicos se dará, nestes casos, também por outras vias: é evidente, por exemplo, a possibilidade de se traçarem, nos casos mencionados de Mendes e Campos, correspondências entre efeitos sonoros (relacionados ao sentido) do texto original e outros obtidos na recriação em português -

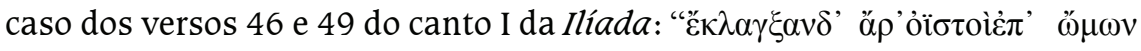

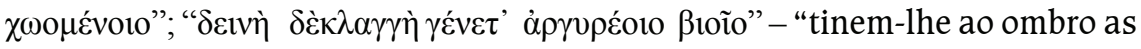
frechas. Ante a frota"; "Terrível o arco argênteo estala e zune", na tradução

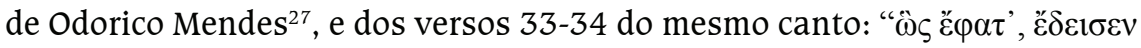

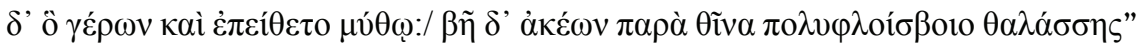
- "Findou a fala e o ancião retrocedeu medroso,/ mudo, ao longo do mar de políssonas praias", na tradução de Haroldo de Campos ${ }^{28}$.

A mesma busca pode envolver a leitura dos versos clássicos conforme um esquema silábico-acentual inserto em nossa tradição, como fez o poeta Guilherme de Almeida em seus estudos para definição de padrões métricos a serem adotados em sua recriação da Antígone $^{29}$, de Sófocles:

25 Haroldo de Campos refere-se à "interessante solução [...] de buscar num verso de dezesseis sílabas o equivalente, em métrica vernácula, do hexâmetro (verso de seis pés) homérico". CAMPOS, H. de. Para transcriar a Ilíada. In: CAMPOS, H. de; VIEIRA, Trajano. Mênis - A ira de Aquiles. São Paulo: Nova Alexandria, 1994. p. 13.

26 Veja-se a referência à utilização recente do hexâmetro dactílico em língua moderna, no artigo: Oliva Neto, João Ângelo; Nogueira, Érico. "O hexâmetro dactílico vernáculo antes de Carlos Alberto Nunes". Scientia Tradutionis n. 13, 2013, pp. 295-310; v. nota 20, p. 300.

27 HOMERo. Ilíada. Tradução: Manuel Odorico Mendes. Prefácio e notas de Sálvio Nienkötter. São Paulo: Ateliê / Campinas: Ed. da Unicamp, 2008, p. 47.

28 CAMPOS, H.; VIEIRA, T. Op. cit., p. 33. Ou: Campos, Haroldo de. Ilíada de Homero. São Paulo: Mandarim, 2002, p. 33.

29 ALMEIDA, Guilherme de; VIEIRA, Trajano. Três tragédias gregas. São Paulo: Perspectiva, 1997 , p. 24 


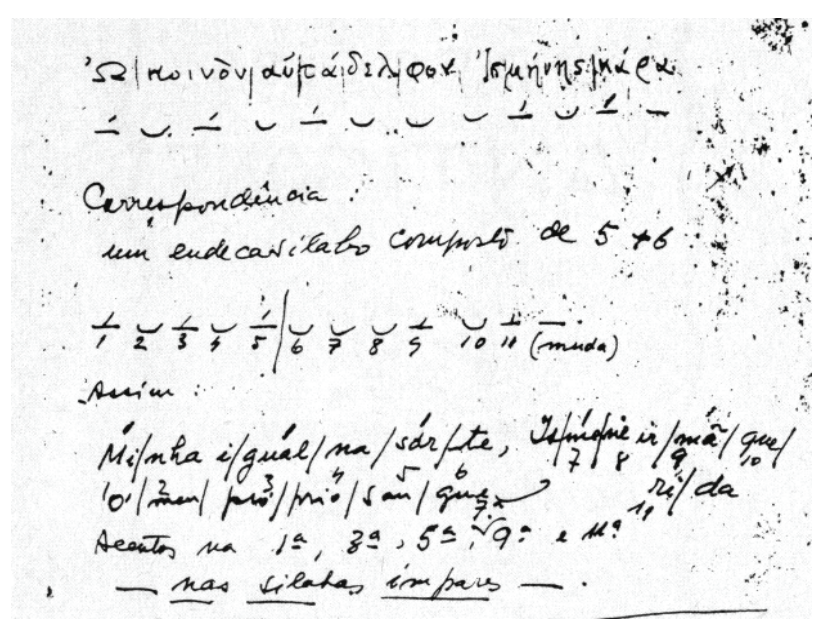

Se as adaptações, mesmo em padrões acentuais uniformes, de metros clássicos, podem ser de difícil apreensão, a dificuldade apontada por Levy certamente pode ser esperada em relação a padrões métricos complexos, como as referidas odes de Píndaro. Tais dificuldades de leitura por si sós indicam a distância entre os sistemas clássicos e os sistemas adaptativos, uma vez que o modo como são percebidos são bastante distintos.

A proposta de equivalência estrita de esquemas métrico-rítmicos em versos de configuração variável - como no caso das odes mencionadas - não é inusitada em nossa língua. Embora relativa a uma poesia bastante diversa da clássica, é possível citar a experimentação, realizada também por Guilherme de Almeida, de recriação de versos ditos "livres" 30 do francês Paul Géraldy baseada na correspondência exata, verso a verso, da medida e do metro inconstantes. Esperar-se-ia, habitualmente, que poemas realizados em versos desiguais dispensassem a procura de correspondência métrica estrita (uma vez que admitem a variabilidade); entretanto, a valorização do aspecto rítmico da poesia no processo de tradução (ou recriação, ou reprodução, como preferiria o tradutor) levou Almeida a optar por tal correspondência:

[...] a dificuldade máxima: a da forma poética, isto é, a do verso livre, adotada pelo poeta francês. [...] Ora, traduzir versos livres no mesmo número e na mesma medida e no mesmo ritmo e com as mesmas rimas e na mesma "maneira" do original, já não é

30 Embora Guilherme de Almeida refira-se aos versos de Géraldy como "livres”, deve-se observar que os poemas de Toi et moi (que não obedecem a formas pré-fixadas) são compostos de versos de métrica irregular, mas cujas medidas muitas vezes se repetem em sequência e ocasionalmente, num espaço de variação delimitado. 
traduzir: é "reproduzir". Reproduzir, num sentido autêntico, total e superior da expressão; quer dizer: produzir de novo. ${ }^{31}$

Trata-se de um exercício que, movido pelo mesmo propósito de correspondência métrica exata, realiza-se entre sistemas cognatos de versificação, e que, portanto, não envolve as questões relativas à adaptação de sistemas diversos.

Mas retornemos à nossa referência inicial - o exercício tradutório de Leonardo Antunes. Este, como diz o próprio autor, adquire proveito adicional em sua busca de desvendamento dos esquemas originais, independentemente de sua eficácia em nossa língua, que pode, contudo, ser maior na medida em que ele se vale da proposta musical das composições: como se sabe, os versos cantados permitem a distinção entre sílabas longas e breves, uma vez que a duração dos sons integra a configuração rítmico-melódica. Assim, a escolha de poemas - e traduções - destinados ao canto poderá, de fato, superar (ao menos em parte) o abismo entre os sistemas de versificação próprios das línguas antigas e modernas, alçando o verso em português, quando cantado, a uma dimensão próxima à de um verso elaborado a partir de um sistema quantitativo, o que atribuiria ao exercício a feição de um trabalho entre sistemas cognatos de metrificação. Esse aspecto não impedirá, diga-se, que se possam perceber - por meio da simples leitura - os versos traduzidos como estruturas variáveis semelhantes ao nosso verso livre, dada a sua mutável e frequentemente longa extensão.

Consideradas possibilidades diversas de adaptação e conversão de padrões rítmicos clássicos a idiomas modernos, é preciso observar que os resultados das composições refletirão, obviamente, os caminhos adaptativos escolhidos por seus autores, mas também as possibilidades diversas de leitura propiciadas por diferentes referências e padrões de reconhecimento próprios de épocas, culturas e idiomas distintos. Como é evidente, a dimensão paródica (entendida, conforme propõe Haroldo de Campos, como "canto paralelo") ${ }^{32} \mathrm{e}$ palimpséstica de toda recriação permite a identidade autônoma e interativa das obras em diálogo; e tal autonomia da obra traduzida encerrará diferenças inevitáveis - e, por conseguinte, âmbitos de não-equivalência - por mais que se busquem soluções de correspondência precisa. Difícil será definir, portanto, qualificativos de superioridade ou inferioridade a resultados estéticos baseados apenas em seus propósitos de equivalência (podendo-se contudo,

31 GÉRALDY, Paul. Eu e você. Tradução de Guilherme de Almeida. 10. ed. São Paulo: Companhia Editora Nacional, 1967. p. 9-10.

32 Vejam-se referências ao conceito nos artigos de Haroldo de Campos: Tradução, ideologia e história e Das estruturas dissipatórias à constelação: a transcriação do "Lance de dados" de Mallarmé. In: op. cit., 2013. p. 37 e 135. 
como é sempre cabível, examinar a coerência e a eficiência de resultados em relação à proposta orientadora de sua execução).

Assim sendo, critérios de equivalência estrita não poderão determinar, por si mesmos, méritos aos resultados deles advindos. Embora haja recorrência de tentativas de exatidão métrica nas recriações, estas convivem com soluções adaptativas que preveem a flexibilização de critérios e as diferenças inevitáveis, voltando-se à procura de equivalência a outros aspectos das poéticas envolvidas. É o que se vê, por exemplo, no caso da tradução realizada por Érico Nogueira dos Idílios, de Teócrito, que visa a superar a restrição da constância rítmica imposta pelo hexâmetro acentual:

\begin{abstract}
Seguindo, pois, o exemplo de Nunes, o que fizemos foi basicamente variá-lo ainda mais, mantendo-nos, com isso, bastante mais fiéis à vivacidade do hexâmetro [...] 0 resultado foi a fabricação, se não propriamente de hexâmetros, ao menos de 'hexatônicos' vernáculos, suficientemente ágeis, contudo, para sugerir, em português, a exuberância do original. ${ }^{33}$
\end{abstract}

Busca-se, assim, nesse trabalho, equivalência aos aspectos de "vivacidade" e "agilidade" atribuídos ao original, o que levará à assunção de um critério não rígido de correspondência dos pés, caracterizado pela incidência de seis acentos nos versos. Estes versos "hexatônicos" seriam, portanto, mais "equivalentes" aos hexamétricos, sob o ponto de vista da dita "vivacidade". Como breve exemplo, seguem-se alguns desses versos:

Eis-me, Tírsis do Etna, de Tírsis a voz é dulcíssima.

$[\cdots]$

Cantai a Bucólica, Musas queridas, cantai a canção.

$[\ldots]$

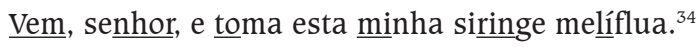

Propósito análogo certamente será encontrado em outras tentativas presentes na história de adaptação dos padrões métricos clássicos, e se encontrará em minha própria proposta de tradução da épica homérica, cuja realização (uma work in progress) se limita à recriação de excertos da obra. Segundo tal proposição, os versos: não terão quantidade fixa de sílabas; terão cinco ou seis acentos (considerando-se a necessidade de marcação 
que reforce a expectativa constante, como marcação rítmica, definindo-se células binárias e ternárias ${ }^{35}$ ); apresentarão, invariavelmente, a chamada "cláusula hexamétrica" (sequência final do verso em que há uma unidade ternária descendente - um pé dáctilo segundo critério acentual, seguida de unidade binária descendente), tomada como sequência definidora, por sua recorrência, de um ritmo dactílico, uma vez que está presente em todos os diversos modos de adaptação do hexâmetro examinados nas fontes de pesquisa. A proposta vale-se, portanto, da adoção do princípio acentual de versificação - que, como se pôde ver, integra a tradição da produção poética em nosso idioma - como fundamento da composição, de modo a que o número de acentos permita a percepção de uma cadência, variável em parte, mas que incorpora um segmento dactílico fixo ao fim de cada verso, correspondendo, assim, à expectativa de repetição ternária como meio de assimilação do hexâmetro. Unir a variabilidade à constância é o objetivo fundamental da proposição, como modo de (re)criar um verso adequado à poética em nossa língua, que guarde - sendo "canto paralelo" - uma relação imitativa com a dinâmica do sistema métrico clássico (no qual, lembre-se, podia haver a substituição do pé dáctilo pelo espondeu, evitada no quinto pé). A quantidade variável de acentos ( 5 ou 6 ) - encontrada entre as propostas históricas de adaptação do verso hexamétrico - não chega a descaracterizar o metro, pois a quantidade mínima mantém a recorrência próxima do padrão esperado, que se completa na sucessão dos versos, amiúde unidos, por enjambement, na sequência narrativa; por sua vez, a quantidade de sílabas dos versos, em decorrência do critério acentual, frequentemente não excede a doze. Para ilustrar o procedimento, incluo, a seguir, os dezenove primeiros versos do canto XI da Odisseia (nos quais se marcam as tônicas consideradas e se anota o número de sílabas, conforme minha leitura):

Ouando, depois, descemos ao mar e ao navio, (12) primeiro ao mar divino o navio empurramos, (12) $\underline{\text { e}}$, da negra nau, o mastro e as velas erguemos; (12) levadas a bordo as ovelhas pegas, seguimos (13) 5 tristes, aflitos, vertendo lágrimas fartas. (12) Por trás da nau de escura proa, Circe, a terrível (13) deusa canora, de belos cachos, envia-nos vento (14) propício, a inflar as velas, ótimo sócio. (12)

35 Considerei admissíveis, no entanto - como se poderá ver nos versos 12 e 15 do fragmento apresentado - a ocorrência eventual de células quaternárias, que, contendo uma sílaba semitônica, poderão ser subdivididas, conforme a reconhecida tendência de leitura baseada nos padrões rítmicos predominantes em nossa língua (binários e ternários). 
Cansados demais por cuidar de apetrechos do barco, (14)

10 sentamos; o vento e o piloto o navio guiavam. (13)

Por todo o dia singramos, velas infladas. (12)

Pôsto o sol, cobriram-se de sombra os caminhos: (12)

a nau atinge o limite do oceano profundo. (13)

Lá estão a cidade e o país dos cimérios, (12)

15 pelo véu das nuvens ẹ das brumas envoltos: (12)

Hélio raios-brilhantes nunca sob si os vislumbra, (14)

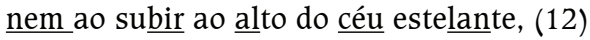

nem ao baixar, de novo, do páramo à terra: (12)

estira-se a noite fatal sobre os pobres humanos. (14)

\section{REFERÊNCIAS}

ALMEIDA, Guilherme de; VIEIRA, Trajano. Três tragédias gregas. São Paulo: Perspectiva, 1997.

ANTUNES, Carlos Leonardo Bonturim. Métrica e rítmica nas Odes píticas de Píndaro. Tese (Doutorado) - Departamento de Letras Clássicas e Vernáculas, FFLCH-USP, São Paulo, 2013.

BILAC, Olavo; PASSOS, Guimarães. Tratado de versificação. Rio de Janeiro: Livraria Francisco Alves, 1910.

BRITTO, P. H. O conceito do contraponto métrico em versificação. Poesia Sempre, Rio de Janeiro, n. 31, p. 71-83, 2009.

CAMPOS, Haroldo de. Ilíada de Homero. São Paulo: Mandarim, 2002.

CAMPOS, H. de; VIEIRA, Trajano. Mênis - A ira de Aquiles. São Paulo: Nova Alexandria, 1994.

GREENE, Roland (editor in chief). The Princeton Encyclopedia of Poetry \& Poetics. 4. ed. Princeton e Oxford: Princeton University Press, 2012.

CASTILHO, A. F. de. Tratado de metrificação portuguesa - Para em pouco tempo, e até sem mestre, se aprenderem a fazer versos de todas as medidas e composições. Lisboa: Imprensa Nacional, 1851.

. Tratado de metrificação portuguesa - Seguido de considerações sobre a declamação e a poética. 4. ed., revista e aumentada. Lisboa: Livraria Moré-Editora, 1874.

GÉRALDY, Paul. Eu e você. Tradução de Guilherme de Almeida. 10 ed. São Paulo: Companhia Editora Nacional, 1967.

HOMERO. Ilíada. Tradução: Manuel Odorico Mendes. Prefácio e notas de Sálvio Nienkötter. São Paulo: Ateliê / Campinas: Ed. da Unicamp, 2008. p. 47.

KAYSER, Wolfgang. Análise e interpretação da obra literária. Coimbra: Arménio Amado Editor / São Paulo: Livraria Martins Fontes, 1976. 
TÁPIA, M. QUestões de EQUIVALÊNCIA MÉTRICA EM TRAdUÇão DE POESIA ANTIGA

LEECH, G. A linguistic guide to English Poetry. London: Longman, 1969.

LEVY, J. The art of translation. Translation: Patrick Corness. Amsterdam / Philadelphia: John Benjamins Translation Library, 2011.

NOGUEIRA, Érico. Verdade, contenda e poesia nos Idílios de Teócrito. São Paulo: Humanitas, 2013. p. 132.

OLIVA NETO, João Ângelo; NOGUEIRA, Érico. O hexâmetro dactílico vernáculo antes de Carlos Alberto Nunes. Scientia Traductionis, Florianópolis, n. 13, p.295-311, 2013.

PEJENAUTE, F. La adaptación de los metros clasicos en castellano. Estudios clasicos, Madrid, n. 63, p. 213, 1971.

PROENÇA, M. Cavalcanti. Ritmo e poesia. Rio de Janeiro: Organização Simões, 1955.

PYM, Anthony. Teorias contemporaneas de la traducción. In: site da Universitat Rovira i Virgili. Tarragona (Catalunha, Espanha): 2011.

RAMOS, Péricles Eugênio da Silva. Os princípios silábico e silábico-acentual. In: $O$ verso romântico e outros ensaios. São Paulo: Conselho Estadual de Cultura, 1959.

TÁPIA, Marcelo. Diferentes percursos de tradução da épica homérica como paradigmas metodológicos de recriação poética - um estudo propositivo sobre linguagem, poesia e tradução. Tese (Doutorado) - Departamento de Teoria Literária e Literatura Comparada, FFCLH-USP, São Paulo, 2012.

TÁPIA, Marcelo; NÓBREGA, Thelma Médici (orgs.). Haroldo de Campos - Transcriação. São Paulo: Perspectiva, 2013.

Submetido em: 18/02/2014

Aceito em: 24/04/2014 